\title{
Cognitive Process Students In Mathematical Problem Solving In Productive Connectivity Thinking
}

\author{
Turmudi ${ }^{1}$, Elly Susanti ${ }^{2}$ \\ ${ }^{1.2}$ State Islamic University Maulana Malik Ibrahim Malang \\ ${ }^{1}$ turmudi_msi@yahoo.com, ${ }^{2}$ ellysusanti@mat.uin-malang.ac.id
}

\begin{abstract}
The main factor causing student obstacles in solving math problems is that students can not connect between related concepts, resulting in construction holes in the structure of thinking. Therefore it is important to do research that aims to overcome obstacles in the students as a subject of learning. How cognitive structure of students who have complete connections and descriptions about the process of formation of the scheme becomes the formulation of the problem in this study. Data Research in the form of student work, think aloud, and in-depth interviews are analyzed by the construction of thinking when students connect mathematical concepts. The results showed that the formation of thought processes in building a network of connective thinking scheme when students have the ability to represent concepts from one form to another so that students can link mathematical ideas built from the results of such representation. Furthermore, the connective thinking network scheme formed has productive properties that can be reconstructed into new connective thinking network schemes that can be generalized and implemented into more complex problem-solving domains.
\end{abstract}

Keywords - Cognitive process, mathematical problem solving, productive connectivity thinking

\section{Preliminary}

The study was based on theoretical and empirical study on the factors that cause learning difficulties students in an $\mathrm{m}$ emecah $\mathrm{k}$ math problems. Observation on the learning process of 60 students S MA shows that (1) students can not connect mathematical concepts so students have trouble solving problems as much as $60 \%$; (2) students can connect mathematical concepts in the given problem situation but not as complete as $30 \%$, so that students can not solve the problem given ; (3) students can connect mathematical concepts in the given problem situation as much as $10 \%$, so that students have no trouble in solving math problems.

Mathematical problem solving involves a thought process. (Solso, 2008) states that thinking is a cognitive process in transforming information through interaction between a mental attributes such as abstraction, logic, and problem solving. The cognitive process is a process of construction or reconstruction of an old knowledge scheme into a new knowledge scheme (Bartlett, 1932). The construction process or the construction of conception into a complete knowledge scheme as a whole of the whole thinking process can be regarded as a global concept (Gredler, 2005). Theoretically, s students have difficulty solving math problems (observation 1) because in the students' thinking process there is no construction or reconstruction of the old knowledge scheme into a new knowledge scheme. According to (Subanji., 2011), the difficulty is caused by the incapacity of students' thinking structures with problem structures encountered. The structure of thinking is a cognitive scheme that is formed when students solve problems. Subanji (2011) states that

In the problem-solving process, when the problem structure faced by a person is much more complex than the structure of thinking it will be difficult to assimilate (there is no scheme of thought appropriate to the problem structure) and accommodation (not enough schemes that can be used to convert the old scheme into a scheme new).

Students' thinking structures vary from one student to another. This difference in thinking structure is influenced by differences in cognitive skills possessed by students. Cognitive skills are closely related to ideas that arise when students engage in thought processes so that the processing of conceptions in everyone's mind varies from one another (Isoda, 2012). Formation of a complete thinking structure, in addition to requiring cognitive skills as well as systematic thinking processes. (Holyoak, 2012) states that "Definition of thinking is about: T hinking is the systematic transformation of mental representations of knowledge. A mental representation of knowledge is an internal description that can be manipulated to form other descriptions". Students who have a systematic way of thinking can download right information sequentially transforma tion the right of representation me his knowledge so as to form a mental description that can be manipulated to form other mental description . 
(Susanti, 2015) research result is thinking productive connectivity is the process of thinking in building a network of connecting thinking schemes in which the mathematical ideas that build the scheme are diverse and complete so that the scheme can be reconstructed into a newly formatted and interpreted network of thought-binding schemes that become more complex. problem-solving domain. In establishing mathematical connections, students can form their thinking structures according to the structure of the given problem. In establishing the connection, sISWA the structure of his thinking is in conformity with the structure of the given problem can mato the process of (1) the organization of ideas and other important processes insolving mathematical problems; (2) attribution of mathematical ideas from problem to issue, investigation to inquiry, unity to unity of lesson, and topic from class to class; (3) organizing ideas in developing reasoning (NCTM., 2000). Based on the above study, building an important mathematical connection for teachers to design learning models. $\mathrm{M}$ embangun association between mathematical ideas in solving mathematical problems involving the thinking of students. Therefore in this research need to be studied and studied about " cognitive process $\mathrm{s}$ students in solving mathematical problems at the level of productive connectivity thinking ".

\section{Theoritical Review}

(Holyoak, 2012) say that " Definition of thinking is about: $T$ hinking is the systematic transformation of mental representations of knowledge, a mental representation of knowledge is an internal description that can be manipulated to form other descriptions". Thinking is a cognitive process in transforming information through mental representation. This mental representation is a constructive and reconstructive process of information into a knowledge (Tall, 1999). Mental representation is an internal description that can be manipulated to form other mental descriptions. The use of this internal description manipulation can help students develop their ideas. This is in line with Puchner's, Taylor's, O'Donnell, \& Fick (2008) remarks that " making decisions about manipulative use, including when and how to think about mathematical ideas more closely" .

(Hiebert, 1999) say that mathematical connections are part of an interconnected network of knowledge packs consisting of toy concepts so that students can use to understand and develop relationships between facts, mathematical ideas, concepts, and procedures. Building a mathematical connection of two representations is to change a representation from one mode to another or to transform the form of a representation to another in the same fashion (Lesh, 1983). For example, if the student identifies a function graph into a logarithmic function formula, then the student performs a representation of the image mode into the writing mode as in Figure 2.1. The representation is a connection between geometry and algebra.

(Susanti \& Faida, 2017) The study found there are seven types of connections built by students when solving verbal problems, namely: understanding connections, connections if so, equivalent representational connections, hierarchical connections, comparison connections through common forms, connection procedures, and connection justification and representation.

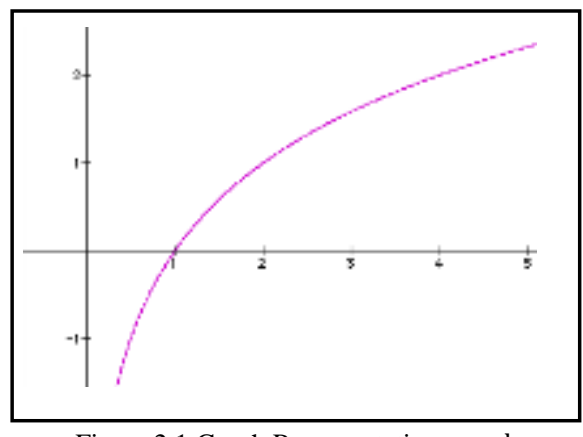

Figure 2.1 Graph Representation $\mathrm{y}=\log _{2} x$

If students write back the form of representation $\log _{2} x=y$ as $y=\frac{\log x}{\log 2}$, then the student changes the representation in writing mode.

The process of finding multiplication algorithms through the meaning of numbers $(x+3)$ and $(x+4)$ as a measure in geometry mode is an example of a connection between algebra and geometry. Number $(x+3)$ and $(x+4)$ as an algebraic mode is represented as the length and width in the rectangle building as a geometry mode as in Figure 2.2. The result of the representation of algebra and geometry is a connection process. The product $x^{2}+3 x+4 x+3.4$ of the number is the area of the rectangle.

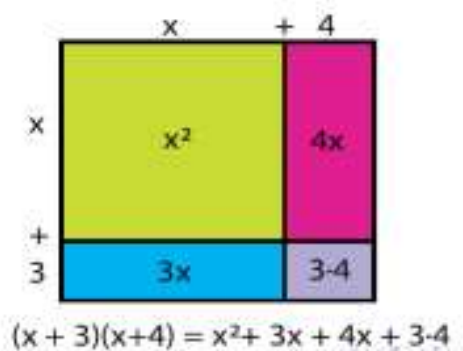

Figure 2. 2 Algebra and Geometry Connections

(Hodgson, 1995) states that the process of finding solutions to the problem of linear equations using graphs is a connection between algebra and geometry.Equation of lines $y=x-1$ represented in the graph in Figure 2.3. The set of points of intersection in the coordinate plane $\mathrm{XY}$ is the solution of the equation of the line $y=x-1$. 
Mathematical connection of the equation of lines $y=x-1$ the graph is an algebraic mode that is represented in geometry mode.

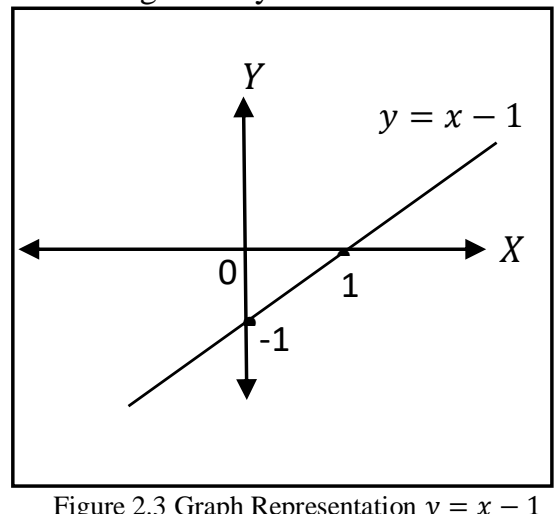

The relationships, principles and ideas of mathematics can be expressed in several representations, including visual representations (diagrams, drawings, and graphs), verbal representations (spoton and written), and symbolic representations (numbers, letters, and numerals). Each type of representation articulates different meanings of mathematical concepts. This is in accordance with the statement of (Panasuk, 2011) is Mathematical relationships, principles, and ideas can be expressed in multiple representations, including visual representations (ie, diagrams, pictures, or graphs), verbal representations (numbers and letters), and symbolic representations (numbers, letters). Each type of representation articulates different meanings of mathematical concepts.

Building a mathematical connection is a cognitive process in making attribution between mathematical ideas. These ideas are communicated as a form of mental representation. Mental representation can not be observed directly, but the mental representation is presented as a form of speech, language, written symbol, image, or other real objects. One example, the concept of waking up can be represented by spatial images. (Heiser, 2004) states that " Spatial representations, both external drawings and internal images, exploit people's sophisticated perceptual-motor system. The embodiment of thought in perceptual processes has promising implications for learning ".

(Pape, 2001) describe mathematical representation as an internal abstraction of mathematical ideas. The interrelationships between these ideas form a thinking scheme. The establishment of a thinking scheme in establishing connections by (Hiebert, 1999) is expressed as a structured knowledge network. This scheme forms a hierarchy when multiple representations classify other representations. This scheme also forms a web of spiders when dots or nodes are considered as representing information, and links between information as a connection.

\section{Discussion of Research Results}

The thought process examined in this study relates to the association of mathematical ideas that arise when students build mathematical connections. The linkage between these ideas builds a network of connective thinking. Some researchers in Karadag (2009) define the process of mathematical thinking as:

Define mathematical thinking as a process, which contains at least one of the mental and math-related activities such as reasoning, abstracting, conjecturing, representing and switching between different representations, visualizing, deducing, inducing, analyzing, synthesizing, connecting, generalizing, and proving.

Based on research data, one of the mental processes undertaton by students is the process of establishing a mathematical connection. The mental process is related to the emergence of ideas when one builds a mathematical connection. This is in line with the research conducted by (Bartlett, 1932) concluded that the process that occurs in memory is a constructive or reconstructive process, rather than a passive activity. If one looks in detail from the concept of being a knowledge scheme and can capture such a scheme as a unity of the connection process then the scheme can be regarded as a global concept.

Proses students thinking in building connection mathematical ideas, the researchers describe concretely the formation of networks of connective thinking. Given thefollowing issues. Complete the by $y=4-$ $f(x), \quad y=4-f(x-4)$ and lines $y=4$, then the area as limit there is.....

The structure of the problem is as follows.

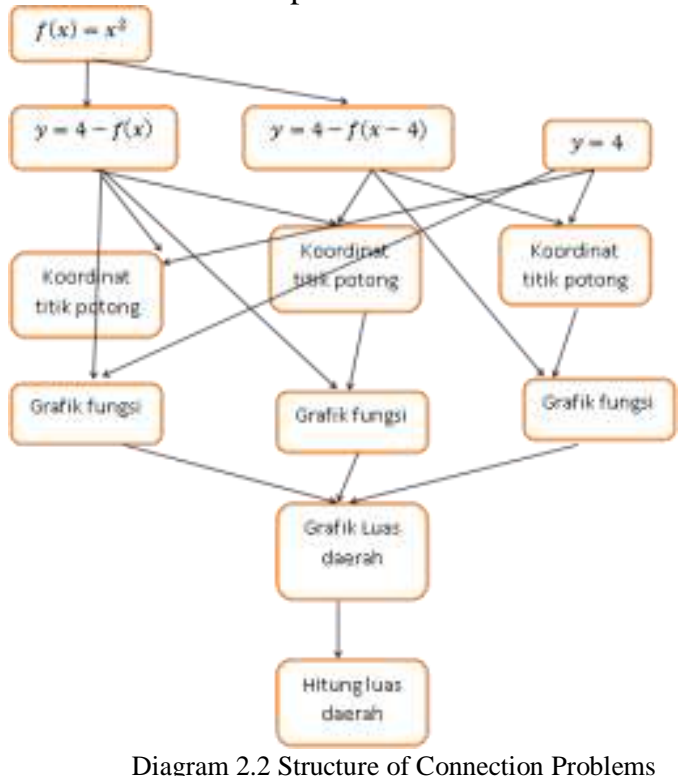

Diagram 2.2 Structure of Connection Problems 
The network of connective thinking in building the linkage between mathematical ideas based on the structure of the problem is illustrated concretely in the following diagram.

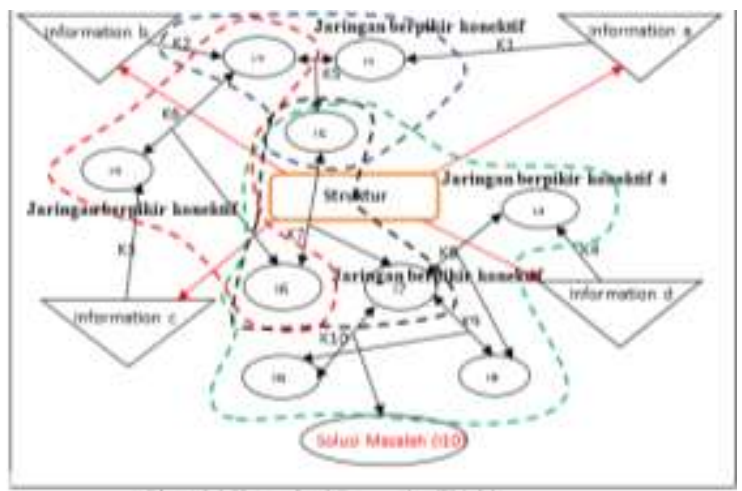

Chart 2.3 Network of Connective Thinking

\section{Description Diagram 2.3}

$\mathrm{K} i=$ Connection to $-i$ and $\mathrm{I} i=$ Idea to- $i$ with $i=1,2$, $3, \ldots, 10$

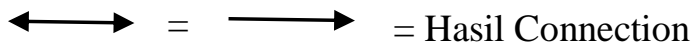

Tabel 2.1

\begin{tabular}{|c|c|}
\hline $\begin{array}{l}\text { Information } \quad \text { a } \quad:= \\
f(x)=x^{2}\end{array}$ & $\begin{array}{l}\text { I } 4:=\text { describe fungtion } \\
y=4\end{array}$ \\
\hline $\begin{array}{l}\text { Information } \mathrm{b}:=y= \\
4-f(x)\end{array}$ & $\begin{array}{l}\text { I5 }:=\text { determine the } \\
\text { coordinates of the } \\
\text { intercept point } f(x)= \\
x^{2} \text { dan } y=4-f(x)\end{array}$ \\
\hline $\begin{array}{l}\text { Information } \mathrm{c}:=y= \\
4-f(x-4)\end{array}$ & $\begin{array}{l}\text { I6 := determine the } \\
\text { coordinates of the } \\
\text { intercept point } y= \\
4-f(x) \text { dan } y=4- \\
f(x-4)\end{array}$ \\
\hline Information $\mathrm{d}:=y=4$ & $\begin{array}{l}\text { I7 }:=\text { the coordinates of } \\
\text { the intercept point } y= \\
4-f(x) \text { dan } y=4- \\
f(x-4)\end{array}$ \\
\hline $\begin{array}{l}\text { I1:= describe fungtion } \\
f(x)=x^{2}\end{array}$ & $\begin{array}{l}\text { I8 }:=\text { determine the } \\
\text { coordinates of the } \\
\text { intercept point } y= \\
4-f(x-4) \text { dan } y= \\
4\end{array}$ \\
\hline $\begin{array}{l}\mathrm{I} 2:=\text { describe fungtion } \\
y=4-f(x)\end{array}$ & $\begin{array}{l}\text { I9 := determine the } \\
\text { slices of the three } \\
\text { function graphs }\end{array}$ \\
\hline $\begin{array}{l}\text { I3 }:=\text { describe fungtion } \\
y=4-f(x-4)\end{array}$ & $\begin{array}{l}\text { I10:= calculate the } \\
\text { shaded area (Problem } \\
\text { Solution) }\end{array}$ \\
\hline
\end{tabular}

\section{Explanation Diagram 2.3:}

Given a problem structure containing four subinformation. Based on sub informations $\mathrm{a}, \mathrm{b}, \mathrm{c}$ and $\mathrm{d}$ comes the ideas ideas I1, I2, I3 and I4. Connection $\mathrm{K} 5:=\mathrm{I} 1 \leftrightarrow \mathrm{I} 2 \rightarrow \mathrm{I} 5$ is built on the relationship between $\mathrm{K} 1:=\mathrm{a} \rightarrow \mathrm{I} 1$ and $\mathrm{K} 2:=\mathrm{b} \rightarrow \mathrm{I} 2$. Connection
$\mathrm{K} 6:=\mathrm{I} 2 \leftrightarrow \mathrm{I} 3 \rightarrow \mathrm{I} 6$ This connection forms a network of connective thinking 1 . Connection $\mathrm{K} 2:=\mathrm{a} \rightarrow \mathrm{I} 2$ and $\mathrm{K} 3:=\mathrm{c} \rightarrow \mathrm{I} 3$. is built on the connection between $\mathrm{K} 2$. Network of connective thinking 1 and connective thinking network 2 builds K7 connections $\mathrm{K} 7:=\mathrm{I} 5 \leftrightarrow \mathrm{I} 6 \rightarrow \mathrm{I} 7$. These connections form a connective thinking network 3 . Network of connective thinking 1 , network of connective thinking 2, and connective thinking network 3 builds connections $\mathrm{K} 8:=\mathrm{I} 4 \leftrightarrow \mathrm{I} 7 \rightarrow \mathrm{I} 8, \mathrm{~K} 9:=\mathrm{I} 7 \leftrightarrow \mathrm{I} 8 \rightarrow \mathrm{I} 9$ dan $\mathrm{K} 10:=\mathrm{I} 7 \leftrightarrow \mathrm{I} 9 \rightarrow \mathrm{I} 10$. These connections form a network of connective thinking 4. Network thinking is a knowledge scheme to establish an overall connection.

Based on the student's work and think aloud can be analyzed two alternatives of his cognitive structure when m embangun connection: (1) when the network is formed and structured as a hierarchy, multiple representations connect other representations, a thorough representation. Generalization is an example of a comprehensive representation; (2) when networks formed like spider webs, dots or nodes can be considered as parts or represent information, and threads between them as connections or relationships. This is reinforced by research results Swanson (1990) asserts that conceptual learning is an assembly of attributes in cognitive unit schemes to gain ideas. Further Kastberg (2002) explains that representation plays a role in all the mathematical communication used to convey the ideas of the thinking process.

\section{Conclusion}

Based on the above discussion of two network structures that formed when students establish a connection in processing information is a linear connection network and acomplex connection network. A linear connection network is a network that is formed when students connect mathematical ideas through incomplete representation (the connection network is made up of linear and non-branched relationships between ideas). While the complex connection network is a network that is formed when students connect mathematical ideas through representation as a whole (students can generalize the knowledge that has been formed).

The results showed that the formation of thinking processes in building a network of connective thinking scheme when students have the ability to represent concepts from one form to another so that students can link mathematical ideas built from the results of such representation. Furthermore, the connective thinking network scheme formed has productive properties that can be reconstructed into new connective thinking network schemes that can be generalized and implemented into more complex problem-solving domains. 


\section{REFERENCES}

Bartlett, F. C. "Remembering. Cambridge: Cambridge University Press".(1932).

Gredler, M. "Learning and instruction: Theory into practice (5th ed.)". New Jersey: Prentice Hall. (selected chapters). (2005).

Heiser, J. "External Representations as Insights to Cognition: Production and Comprehension of Text and Diagrams in Instructions. Unpublished Doctoral Dissertation",. Stanford University. (2004).

Hiebert, J. \&. (1999). (Ed.). "Learning and Teaching with Understanding. In D. Grouws, , Handbook of Research on Mathematics Teaching and Learning", New York: MacMillan. (pp. 65-97). 1992.

Hodgson, T. "Connections as Problem-Solving Tools", in Connecting Mathematics across the curriculum. Editor: House, P.A. and Coxford, A.F. Reston, Virginia: NCTM. (1995).

Holyoak, K."Thinking and reasoning: A reader's guide. In K.J. Holyoak \& R.G. Morrison",. New York: Oxford University Press. (2012).

Isoda, M. "Problem Solving Approach to Develop Mathematical Thinking" . Teaching Mathematics and Sciences - Vol. 1(2). (2012).

Lesh, R. L. "Conceptual models in applied mathematical problem solving research. In R. Lesh \& M. Landau. Acquisition of mathematical concepts and processes" (pp. 263-343). . New York: Academic Press. (1983).
NCTM. "Principle and Standard for School Mthematics". Reston: The National Council of Tecaher Mathematics. . NewYork. (2000).

Panasuk, R. "Preferred Representations of Middle School Algebra Students When Solving Problems" . The Mathematics Educator, Vol. 13, No. 1, 32-.(2011).

Pape, S. J. "The role of representation(s) in developing mathematical understanding" . Journal for Theory into Practice, 40(2), 118-125. (2001).

Solso, R. "Cognitive Phsicology". Boston: Allyn and Bacon. (2008).

Subanji. "Teori Berpikir Pseudo Penalaran Kovariasional". UM Press Malang. (2011).

Susanti, E."Proses Berpikir Siswa dalam Membangun Koneksi Ide-ide Matematis Pada Pemecahan Masalah Matematika". Malang. (2015)

Susanti, E., \& Faida, T. "Membangun Koneksi Matematis Siswa dalam Pemecahan Masalah Verbal". Tadris Beta Mataram. (2017).

Tall, D. O. "The cognitive development of proof: Is mathematical proof for all or for some". Developments in school mathematics education around the world . (1999).

Z., K. "Analyzing Students' Mathematical Thinking In Technology-Supported Environments". Department of Curriculum, Teaching, and Learning. University of Toronto. (2009). 